\title{
EPIDEMIOLOGICAL FEATURES OF SARS2 COVID-19 OUTBREAK DURING 2020 AMONG RT-PCR CONFIRMED CASES IN ZAKARPATTYA
}

DOI: $10.36740 /$ WLek202104128

\author{
Stepan 0. Karabinyosh, Galina M. Koval \\ STATE HIGHER EDUCATION ESTABLISHMENT UZHHOROD NATIONAL UNIVERSITY, UZHHOROD, UKRAINE
}

\begin{abstract}
The aim: The overall aim of this project was to provide a comprehensive description of epidemiological and demographic features of SARS2 COVID19 outbreak among patients in Zakarpattya oblast during 2020 to define most vulnerable and susceptible groups of population.

Materials and methods: We conducted a retrospective observational descriptive study of the 33190 cases that tested RT-PCR positive for SARS 2 COVI19 in Zakarpattya oblast, studied their comorbidities and concomitant diseases, as well as their clinical and functional outcomes.

Results: Among studied cases: females - $20069(60.47 \pm 0.27 \%)$ and males - $13121(39.53 \pm 0.27 \%)$.

Geographical distribution showed that: 10230 (30.8\%) of cases were registered in district capital Uzhhorod and surrounding area, 3646 (11\%) were registered in Mukachevo district, Tyachivsky district 3235 cases (9.7\%), Vynohradisky district 2627 (7.9\%), other districts had less than $4 \%$. Most patients were within the age group 31 and 70 with a mean age of $47.76 \pm 17.57$ years.

Conclusions: the emergence of current outbreak of SARS-CoV-2 (COVID-19) pandemic is a reminder of how new pathogens can mutate, emerge and rapidly spread through large amount of human population, and cause severe burden to public health and healthcare system is general.
\end{abstract}

KEY WORDS: SARS-CoV-2, COVID-19, Emergence, Distribution, Zakarpattya

Wiad Lek. 2021;74(4):961-965

\section{INTRODUCTION}

Coronavirus infection (COVID19) - is a severe acute respiratory disease caused by novel coronavirus which belongs to Coronaviridae family. They are positive-sense RNA viruses and may infect a large amount of hosts. Gene sequencing and phylogenetic study shows that SARS-CoV2 which caused the world pandemic outbreak belongs to the order Nidovirales, family Coronaviridae, subfamily Orthocoronavirinae, genus Betacoronavirus. It has the genera Alphacoronavirus and Betacoronavirus originate from bats [1].

The first cases of novel COVID-19 disease were registered in December of 2019 in Wuhan, China [2]. It occurred through zoonotic transmission and was related to seafood market infection. However, later it has been reported that the disease was rapidly spreading from human-to-human and that the actual numbers were underestimated [3].

Covid19 is a highly contagious respiratory infectious disease usually manifested with mild symptoms (around $80 \%)$ or even asymptomatic (1-2\%). The median age of COVID-19 cases ranges from 49 to 57 years [4].

Transcarpathian region (Zakarpattya oblast) is a western administrative division of Ukraine, which borders with four European countries such as Poland, Slovakia, Hungary and Romania. The number of Ukrainian immigrants in neighbouring European countries accounts a large population [5].
Such location of the district and its geopolitical issues related to immigration plays a crucial role in diseases transmission and serves as a gate to infectious diseases to and from European Union [6].

According to the reports of Ministry of Healthcare of Ukraine the first case in Ukraine has been registered on March 3, 2020 in Chernivtsi. On March 13, the first fatal case of coronavirus infection was recorded. According to the System of monitoring of the distribution of COVID infection "SOTA" which is powered by National Security and Defense Council of Ukraine and other open source data provided by Ministry of Healthcare of Ukraine, as of February 14, 2021, there were 1271143 infected people in Ukraine, of whom 24330 died (1.9 $\pm 0.01 \%), 1114301$ recovered $(87.66 \pm 0.03 \%)$, 132512 currently ill (10.4 $\pm 0.03 \%)$ and 1387290 cases suspected with disease (result anticipated).

The outbreak made a tremendous impact on quality of life in general, as well as it is being a huge burden on healthcare system and economy of the country. The most cases were registered in the capital of the country 111471 cases, followed by Odessa oblast 71125 cases, Kharkiv oblast 69 377 cases, and Lviv oblast 61268 cases. Which can be explained by the fact that these are the biggest transportation hubs of the country. It has been observed that there is a significant correlation between amount of transportation and cumulative cases of COVID19 [7]. 


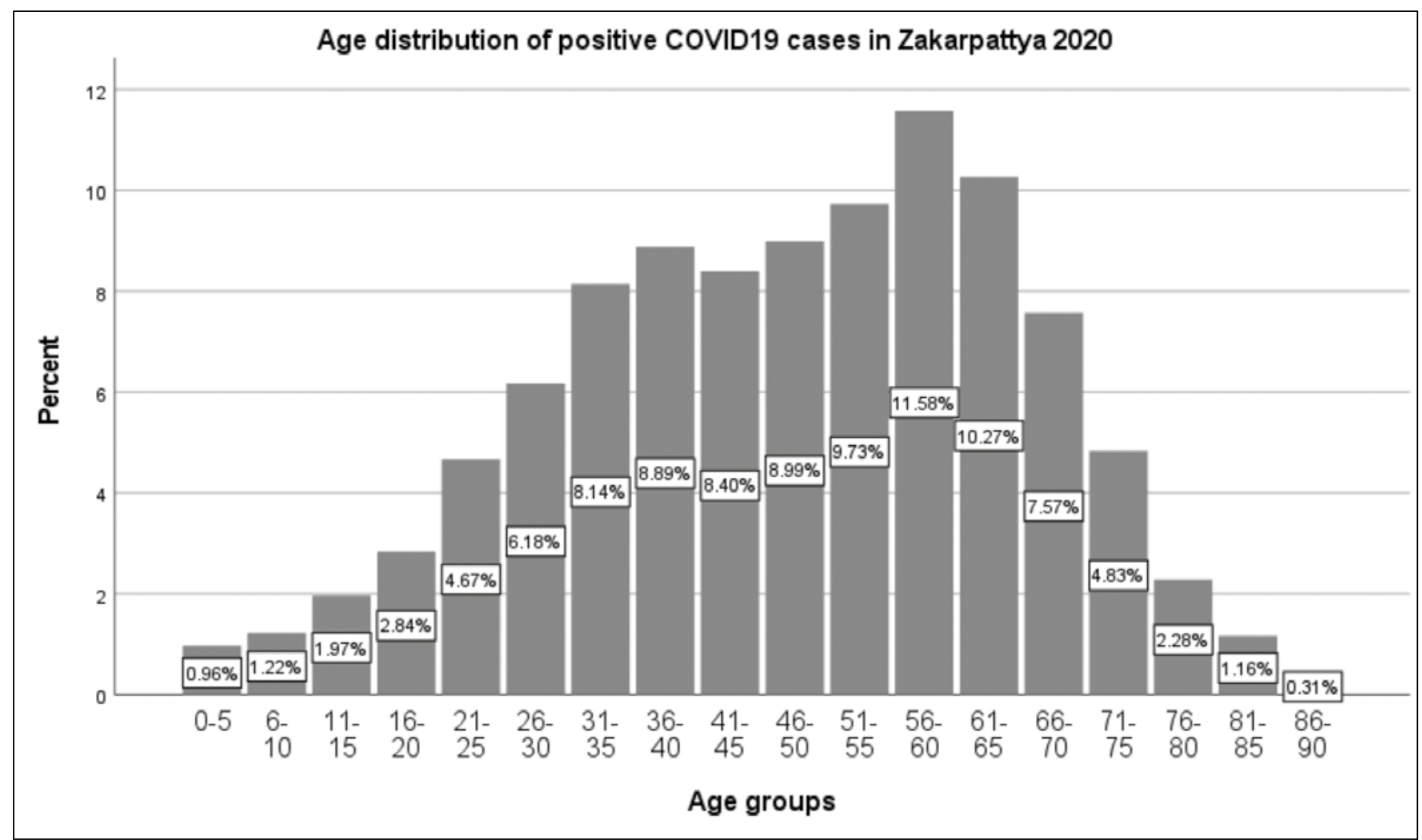

Fig. 1. Age groups of patients who were tested RT-PCR positive for COVID19 in Zakarpattya oblast in 2020.

\section{THE AIM}

The overall aim of this project was to provide a comprehensive description of epidemiological and demographic features of SARS2 COVID19 outbreak among patients in Zakarpattya oblast during 2020 to define most vulnerable and susceptible groups of population.

\section{MATERIALS AND METHODS}

We conducted a retrospective observational descriptive study of the 33190 cases that tested RT-PCR positive for SARS 2 COVI19 in Zakarpattya oblast and registered in Electronic Integrated Information System for Infectious Disease Surveillance (ELISS), studied their comorbidities and concomitant diseases, as well as their clinical and functional outcomes.

\section{RESULTS}

Among studied cases: females - $20069(60.47 \pm 0.27 \%)$ and males - 13121 (39.53 $\pm 0.27 \%)$. Almost 8\% (2 588 cases) were healthcare workers.

Geographical distribution (Table. I) showed that: 10230 (30.8\%) of cases were registered in district capital Uzhhorod and surrounding area, 3646 (11\%) were registered in Mukachevo district, Tyachivsky district 3235 cases (9.7\%), Vynohradisky district 2627 (7.9\%), other districts had less than $4 \%$.

Most commonly patients who were tested positive were within the age group between 31 and 70 with a mean age of 47.76 (95\% CI 47.57 - 47.95) (Fig. 1). The oldest patient was 97 years old who successfully recovered from the disease. However, we studied age distribution divided into groups, and discovered that the biggest number falls between 56 - 60 years $-11.58 \%$ ( 3839 cases), followed by age group $61-65-10.27 \%$ (3 406 cases), and $51-55$ years $-9.73 \%$ (3 226).

There was also some certain seasonality observed with the highest number of cases per day in November $(09 \mathrm{Nov}$ 2020 - 490 cases) (Fig. 2) with mean of case reporting $105 \pm 5.21$ (95\% CI 94.77 - 115.28).

With regards to hospital care - 7363 (22.2\%) cases were hospitalized to inpatient facility, and 25724 (77.5\%) were treated in outpatient clinic. Among analysed cases 9557 (28.8\%) had concomitant diseases: Cardiovascular diseases: 6727 (20.3\%), Diabetes: 1223 (3.7\%), 2\% had chronic lung diseases, $1.7 \%$ of cases had chronic neurological or neuromascular diseases or oncology, and approximately $1 \%$ reported chronic liver or kidney diseases (Table II). However, 3363 (10\%) were unable to respond whether they have any chronic conditions or diseases. Though, only $10 \%$ required oxygen insufflation and $3.8 \%$ had Acute Respiratory Distress Syndrome and were admitted to intensive care facility.

Out of analysed cases (Table III), with obtained information on the outcome $(n=4016)$ : 726 cases $(2.2 \%)$ resulted in fatality, 27874 cases $(84 \%)$ recovered, and $573(12.1 \%)$ cases were remaining ill at the moment of data analysis. 
Table I. Distribution of COVID19 among districts of Zakarpattya oblast during 2020

\begin{tabular}{ccc}
\hline Name & $\mathbf{N}$ & $\%$ \\
\hline 1. Beregivsky & 1729 & $5.2 \%$ \\
\hline 2. Velykobereznyansky & 1230 & $3.7 \%$ \\
\hline 3. Vynogradivsky & 2627 & $7.9 \%$ \\
\hline 4. Volovetsky & 660 & $2.0 \%$ \\
\hline 5. Irshavsky & 1600 & $4.8 \%$ \\
\hline 6. Mizhgirsky & 1090 & $3.3 \%$ \\
\hline 7. Mukachivsky & 3646 & $11.0 \%$ \\
\hline 8. Perechynsky & 1713 & $5.2 \%$ \\
\hline 9. Rahivsky & 2253 & $6.8 \%$ \\
\hline 10. Svalyasky & 1215 & $3.7 \%$ \\
\hline 11. Tyachisky & 3235 & $9.7 \%$ \\
\hline 12. Uzhgorodsky & 10230 & $30.8 \%$ \\
\hline 13. Hustsky & 1657 & $5.0 \%$ \\
\hline 14. Chopsky & 305 & $0.9 \%$ \\
\hline
\end{tabular}

\section{DISCUSSION}

The distribution of the disease shows prevalence of cases in highly populated area like district capital. However, this also may be explained by lack of accessibility to healthcare facilities in remote mountain areas.

We also suggest that such distribution could also be due to the fact, that the districts with highest number of cases are located near border crossing points and therefore have large number of incoming people from abroad. The least cases are on the border with two of Ukrainian oblast Lviv and Ivano-Frankivsk (Fig. 3), even though Lvivska oblast accounted to one of the biggest numbers of positive cases in the country in $2020-61268$ cases $(5.81 \pm 0.02 \%)[6,8,9]$.
Among the analyzed cases majority $77.5 \%$ were treated at outpatient clinic and only $22.2 \%$ required specialized care at inpatient facility. According to the local Standard of Covid19 diagnostic and treatment, the most common indications for hospitalization: moderate and severe course of the diseases, ARDS, severe intoxication, sepsis, etc. However, studies show that only $5-10 \%$ require specialized care. This can be explained, with the fact that majority of hospitalized cases were admitted without actual need and were due to miscommunication regarding actual state of the patient. [10]

The study we performed shows that cardiovascular diseases and hypertension are the most common comorbidities among COVID-19 cases that we analysed which have also been described in the literature. Comorbidities reported by patients show that majority were not previously informed about their underlying diseases. This can be explained with the fact that medical reform in Ukraine is still being implemented and some patients do not have their permanent general practitioner or family doctor yet, and therefore unaware of any chronic diseases. [11]

The study was limited to data available in the reports submitted to ELISS. Further studies should follow up with analysis of patients who were hospitalized, because it would give a greater perspective and understanding of clinical manifestation, treatment outcome and prognosis of the disease depending on the severity.

\section{CONCLUSIONS}

The emergence of current outbreak ofSARS-CoV-2 (COVID-19) pandemic is a reminder of how new pathogens can mutate, emerge and rapidly spread through large amount of human population, as well as cause severe burden to public health and healthcare system is general. Further research must be conducted to establish the fea-

Table II. Frequency of concomitant diseases in positive COVID19 cases in Zakarpattya during 2020

\begin{tabular}{ccccccc}
\hline \multirow{2}{*}{ Valid } & \multicolumn{5}{c}{ Presence of concomitant diseases } \\
\cline { 2 - 6 } & Unknown & Frequency & Percent & Valid Percent & Cumulative Percent \\
\cline { 2 - 6 } & No & 3363 & 10.1 & 10.1 & 10.1 \\
\cline { 2 - 6 } & Yes & 20270 & 61.1 & 61.1 & 100 \\
\hline
\end{tabular}

Table III. Outcome of the COVID19 infection among positive cases in Zakarpattya during 2020.

\begin{tabular}{|c|c|c|c|c|c|}
\hline \multicolumn{6}{|c|}{ Outcome of COVID19 infection } \\
\hline & & Frequency & Percent & Valid Percent & Cumulative Percent \\
\hline \multirow[t]{6}{*}{ Valid } & & 4016 & 12.1 & 12.1 & 12.1 \\
\hline & Remains ill & 573 & 1.7 & 1.7 & 13.8 \\
\hline & Unknown & 1 & .0 & .0 & 13.8 \\
\hline & Recovery & 27874 & 84.0 & 84.0 & 97.8 \\
\hline & Deceased & 726 & 2.2 & 2.2 & 100.0 \\
\hline & Total & 33190 & 100.0 & 100.0 & \\
\hline
\end{tabular}




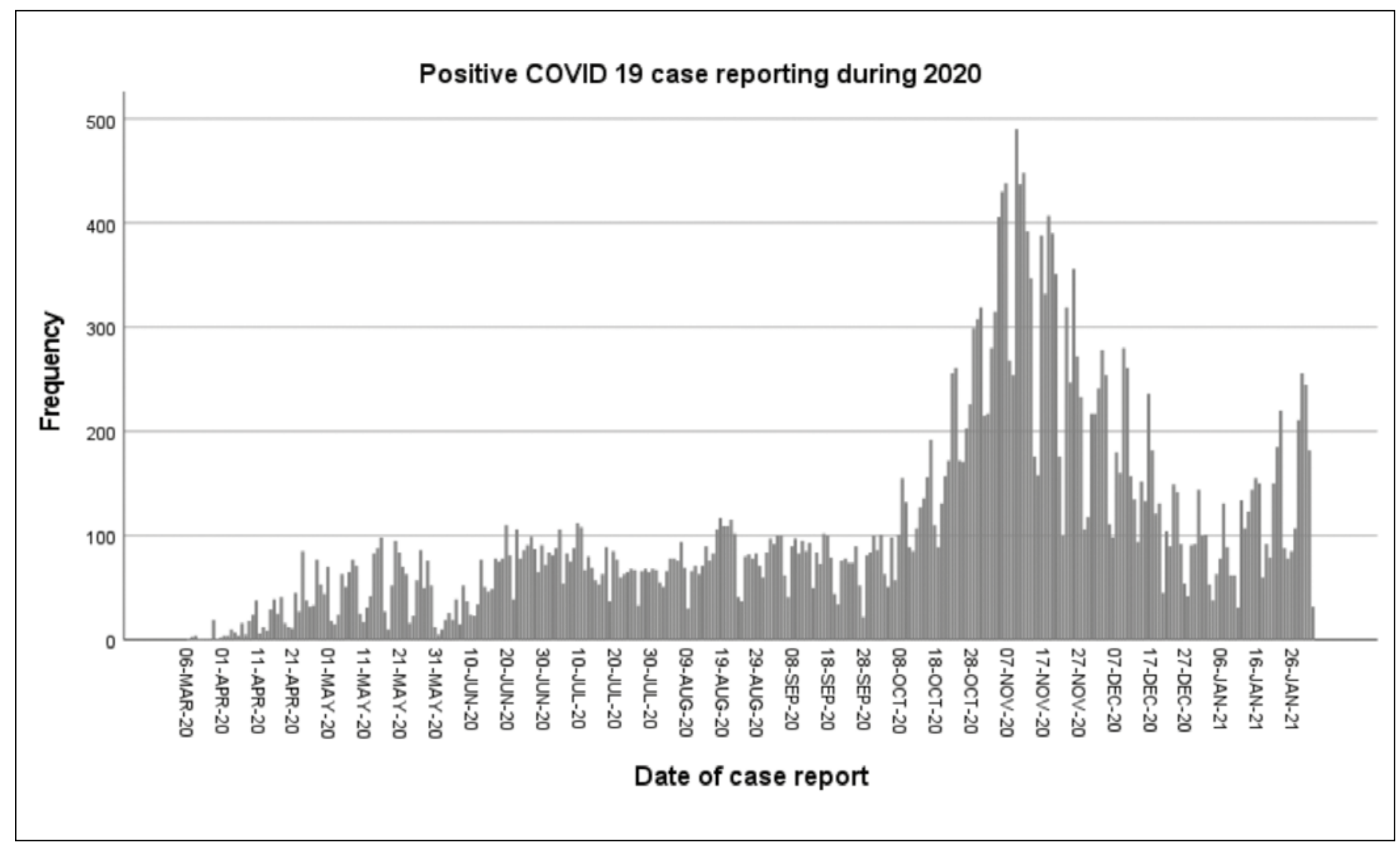

Fig. 2. Seasonal reporting of COVID19 cases in Zakarpattya during 2020.

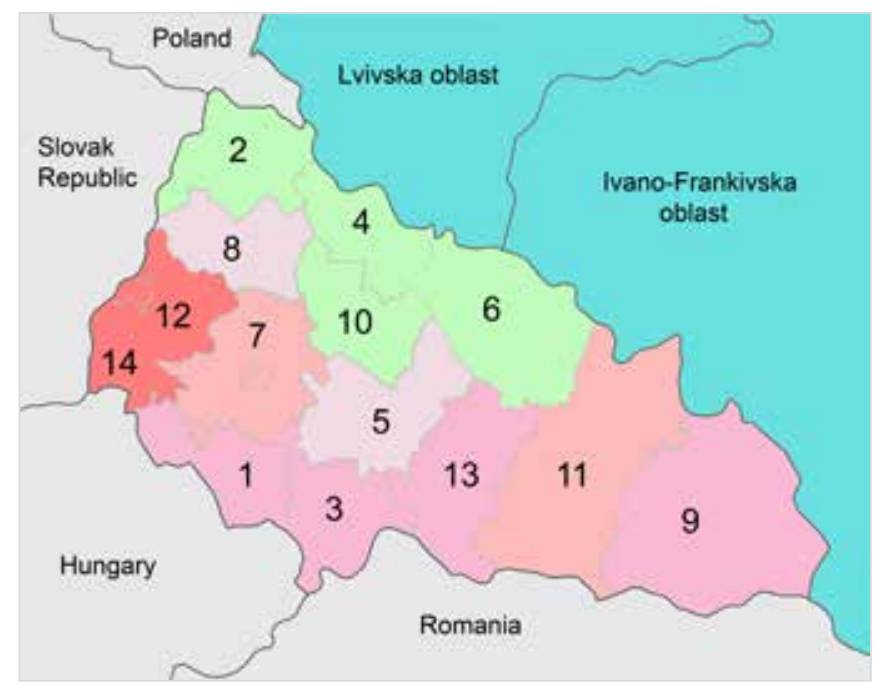

Fig. 3. Geographical distribution of RT-PCR positive cases of Zakarpattya oblast by district

* Districts (rayon) of Zakarpattya oblast: 1 - Beregivsky, 2 -Velykobereznyansky, 3 - Vynogradivsky, 4-Volovetsky, 5 - Irshavsky, 6-Mizhgirsky, 7-Mukachivsky, 8 - Perechynsky, 9 - Rahivsky, 10 - Svalyasky, 11 - Tyachisky, 12 - Uzhgorodsky, 13 - Hustsky, 14 - Chopsky.

tures of clinical manifestation of COVID-19 among hospitalized patients to better understand the natural history of the disease and its possible complications based on laboratory and instrumental findings. Given the fact that majority of the cases are treated with antibiotics, inpatient and recovered patients should be screened for the possible development of antibiotic resistance.

\section{REFERENCES}

1. Dhama K. et al. Coronavirus Disease 2019-COVID-19. Clin Microbiol Rev/ 2020;33(4).

2. Li Q., G.X., Wu P. et al. Early Transmission Dynamics in Wuhan, China, of Novel Coronavirus-Infected Pneumonia. The New England journal of medicine. 2020;382(13): 1199-1207.

3. Nishiura H., Akhmetzhanov A.R. Initial Cluster of Novel Coronavirus (2019-nCoV) Infections in Wuhan, China Is Consistent with Substantial Human-to-Human Transmission. Journal of clinical medicine. 2020;9(2): 488.

4. Bchetnia M. et al. The outbreak of the novel severe acute respiratory syndrome coronavirus 2 (SARS-CoV-2): A review of the current global status. J Infect Public Health. 2020; 13(11): 1601-1610.

5. Koroutchev R. Economic situation and migration trends of Eastern Slovakia and Transcarpathian Ukraine. Journal of Liberty and International Affairs. 2020;5(3): 9-26.

6. Romero-Severson E.0. et al. Change in global transmission rates of COVID-19 through May 6 2020. PLoS One. 2020; 15(8).

7. Zheng R. et al. Spatial transmission of COVID-19 via public and private transportation in China. Travel Med Infect Dis. 2020; 34:101626.

8. Ministry of Health of Ukraine. Analytical panels and dashboards. 2020. https://covid19.gov.ua/analitichni-paneli-dashbordy.

9. Ke R. et al. Fast spread of COVID-19 in Europe and the US suggests the necessity of early, strong and comprehensive interventions. 2020. doi: 10.1101/2020.04.04.20050427.

10. Toyoshima Y. et al. SARS-CoV-2 genomic variations associated with mortality rate of COVID-19. Journal of Human Genetics. 2020;65:10751082.

11. Sanyaolu A. et al. Comorbidity and its Impact on Patients with COVID-19. SN Compr Clin Med. 2020: 1-8. 
This project has been conducted as part of $P h D$ research "Clinical and Epidemiological features of COVID19 patients hospitalized at the Regional Clinical Infectious Diseases Hospital during 2020".

All data used in this study can be accessed directly through the dashboard of the Public Health Center of the Ministry of Health of Ukraine [https://covid19.rnbo.gov.ua/], as well as on demand from Electronic Integrated Information System for Infectious Disease Surveillance (ELISS) with all parameter values provided in the text of the manuscript.

\section{ORCID and contributionship:}

Stepan O. Karabinyosh: 0000-0002-1252-7462 ${ }^{A, B, C, D}$

Galina M. Koval: 0000-0002-0623-2326 D,E,F

\section{Conflict of interest:}

The Authors declare no conflict of interest.

\section{CORRESPONDING AUTHOR Stepan 0. Karabinyosh \\ Uzhhorod National University \\ 148 Sobranetska st., 88015 Uzhhgorod, Ukraine \\ tel: +380953163221 \\ e-mail:stepan.karabinyosh@uzhnu.edu.ua}

Received: 15.11 .2020

Accepted: 08.03.2021

A - Work concept and design, B - Data collection and analysis, C - Responsibility for statistical analysis,

D-Writing the article, $\mathbf{E}$-Critical review, $\mathbf{F}$ - Final approval of the article 